\title{
Increased Collaboration between the APS and EPS
}

\author{
A statement by $\mathrm{N}$. Bloembergen (immediate past-President of APS) \\ and M. Jacob (President of EPS) published in the March 1992 issues \\ of both Europhysics News and APS News.
}

The American Physical Society (APS) and the European Physical Society (EPS) are seeking closer ties and new impetus to their collaboration. Physicists have often taken the lead in establishing international networks. Traditional activities in organizing conferences and publications have always enjoyed the cooperation of individual physicists from many countries. The planning and organization of research increasingly requires international consultation. The Physical Societies can play an important role in facilitating the contacts between physicists from different countries. They are instrumental in providing a wider perspective on crucial issues in education, funding, and ethics. Physicists would like to see physics alive and strong everywhere and to help colleagues in nations where the pursuit of physics research faces unusual political or economic hardships.

It is our hope that a stronger collaboration between the APS and the EPS will respond to the need for worldwide perspectives in physics collaboration. During the past year the two societies have established closer links which may soon bear fruit. A large part of the activity in both societies is channeled through divisions and topical groups which focus on a particular subfield of physics. Many joint activities between the societies, especially relating to research and conferences, can best be handled by direct contacts between the corresponding sub-divisions of the two societies. Channels to accomplish this have been setup. This should facilitate the organization of joint workshops and conferences. Larger issues of interaction relating to public affairs and education can best be handled by direct contact between the executive boards of the two societies.

A few words of introduction of the societies to each other is in order. The structure of physics in Europe is more fragmented than in the United States. The EPS is both an association of twenty-seven national physics societies which have important activities of their own, and a society with a membership of individuals. The number of national societies will soon increase because of current developments in Europe. Ever since its founding twenty-three years ago, the EPS has sought to bring together physicists from Western and Eastern Europe. Channels of communications between East and West had been set up while the Iron Curtain still existed. Now the political barriers have vanished and ample opportunities for new ventures exist to help our colleagues in Central and Eastern Europe in these times of rapid changes in science funding. A close collaboration between the
APS and EPS would be very worthwhile. The EPS could serve as a conduit between the APS and Eastern Europe. Collaborations are most efficiently implemented and developed through a "bottom-up" procedure, and they are most efficiently assessed through international peer reviews. Preparing for that, physical societies are instrumental in providing contacts and in channeling information between people. There is also much to do together when addressing "North-South" problems. The EPS has instituted Divisions and Interdivisional Groups. Thus physicists from a particular subfield from all over Europe can act together. The EPS Divisions have become the natural, active organizers for many international conferences. Direct collaboration on the divisional level between the APS and EPS is strongly encouraged.

Both societies publish a monthly newsletter: Europhysics News and APS News. The latter appears in a new format, as of January, 1992. The former surveys the "life of physics" in Europe and contains details about opportunities in physics offered through the European Economic Community and through various international research organizations.

The EPS does not have a strong publishing role, though it is directly involved in the publication of Europhysics Letters. In Europe, scientific publishing is indeed to a large extent in the hands of commercial publishing companies. These are, however, associate members of the EPS. Discussion channels on editorial policy and long-range planning (electronic publishing) do exist. The situation of physics publishing in the United States is, of course, very different. The APS publishes directly the Physical Review, Physical Review Letters, and the Reviews of Modern Physics. It is to be noted that over fifty percent of the articles published in these journals has authorship from outside the United States. It is less well known in Europe that many other physics journals, including Physics Today, Applied Physics Letters, and the Journal of Chemical Physics, are published by the American Institute of Physics (AIP). The AIP is an organization of ten societies, including The American Physical Society, the Geophysical Union, the Optical Society of America, and the American Association of Physics Teachers. The AIP has associate membership for industrial organizations and some foreign societies may also be affiliated with AIP. The EPS might wish to look into this matter as well. The APS provides a channel of communication between the EPS and AIP. Publication plays a major role in the budgets of both AIP and APS. Exchange of in formation between the APS and EPS on this aspect would be very useful despite the disparity.

The APS and the AIP carry out ongoing studies on education, manpower, and employment opportunities in physics. The EPS has specialized Committees on Physics and Education, Physics and Industry, and Physics and Society, while the APS has forums in these areas. Exchanges of information on these issues between the APS and EPS through their relevant committees will also be of benefit to both societies.

As the year 1991 draws to a close, it is our hope that the APS and the EPS will rapidly expand the existing channels of communication and collaboration to the benefit of physics worldwide.

\section{Announcement from the Publisher of Nuclear Physics}

The Editorial Office of the journals NUCLEAR PHYSICS A and B has been relocated from Copenhagen to Amsterdam.

As from 1 March 1992, the new mailing address is:

Editorial Office of

NUCLEAR PHYSICS

Matrix Building

Science Centre WCW

Kruislaan 419

1098 VA Amsterdam

The Netherlands $\begin{array}{ll}\text { Tel.: } & +31-20-5618161 \text { (Nuclear Physics A) } \\ & +31-20-5618181 \text { (Nuclear Physics B) } \\ \text { Fax: } & +31-20-6654969\end{array}$

e-mail: NPA@NIKHEF.NL (Nuclear Physics A) NPB@NIKHEF.NL (Nuclear Physics B)
Should you have any questions regarding the above, please do not hesitate to call us at +31205862622 or 5862588 .

The journal Nuclear Physics was founded by Leon Rosenfeld in 1957. In 1961, the editor moved to Nordita, Copenhagen. During the following years, the journal received considerable hospitality from Nordita and The Niels Bohr Institute, for which we express our heartiest thanks. The thirty years of close collaboration with the scientific staff in Copenhagen, have in no small way contributed to the current standing of the journals. We trust that in the coming years in the new environment close to NIKHEF, the do NIKHEF, the day to day interaction of the editorial staff with top-level research scientists will continue and will contribute to the further success of the journals.

\section{NORTH-HOLLAND}

P.O. Box 103, 1000 AC Amsterdam, The Netherlands 